\title{
RECENTES AVANÇOS NA PREPARAÇÃO DE AZIRIDINAS. APLICAÇÕES SINTÉTICAS E IMPLICAÇÕES MECANÍSTICAS
}

\author{
Tula Beck Bisol e Marcus Mandolesi Sá* \\ Departamento de Química, Universidade Federal de Santa Catarina, CP 476, 88040-900 Florianópolis - SC, Brasil
}

Recebido em 22/8/05; aceito em 3/2/06; publicado na web em 30/8/06

\begin{abstract}
RECENT ADVANCES IN THE PREPARATION OF AZIRIDINES AND THEIR APPLICATION IN ORGANIC SYNTHESIS. This article surveys a selection of the most recent advances in aziridine synthesis. Novel synthetic methods and new insights into existing methodologies for the selective construction of the title compounds reported in the past decade are discussed in terms of synthetic applicability and environmentally benign conditions. Mechanisms involving stereoselective preparation of structurally diverse aziridines are also presented in order to highlight the most important issues associated with the synthesis of these versatile building blocks.
\end{abstract}

Keywords: aziridines; synthetic methods; heterocycles.

\section{INTRODUÇÃO}

Diversas substâncias biologicamente ativas e heterociclos de origem natural possuem átomos de nitrogênio em suas estruturas, sendo empregados na preparação e formulação de diversos produtos e bens de consumo, como fármacos, artigos de higiene, insumos agrícolas e materiais de uso doméstico ou industrial. A importância de compostos nitrogenados em síntese ${ }^{1}$ vem motivando o desenvolvimento de novas estratégias ${ }^{2}$ para a introdução seletiva de grupos aza-funcionalizados, a partir de metodologias simples ${ }^{3}$ envolvendo condições reacionais brandas, alta economia atômica, reagentes e produtos atóxicos, geração mínima de resíduos e reduzido impacto ambiental ${ }^{4-6}$.

Aziridinas são heterociclos nitrogenados de 3 membros intensamente estudados nos últimos anos, em parte por serem consideradas ${ }^{7}$ como os aza-análogos de epóxidos, mas sobretudo por apresentarem propriedades químicas e biológicas ${ }^{8-10}$ bastante peculiares. Apesar de serem sistemas reativos (principalmente devido à tensão anelar e à polarização das ligações $\mathrm{C}-\mathrm{N}$ ), aziridinas de alto peso molecular normalmente possuem elevada estabilidade à temperatura ambiente. $\mathrm{O}$ núcleo aziridínico ${ }^{10}$ está presente na estrutura de importantes substâncias de ocorrência natural. As mitomicinas são exemplos de aziridinas isoladas de microrganismos ${ }^{11}$ que apresentam elevada atividade antibiótica, enquanto derivados sintéti$\cos ^{12-16}$ como fosforil- e tiofosforilaziridinas exibem atividades antitumoral, mutagênica e inseticida (Figura 1). Já aziridinas mais simples, como etilenoimina e propilenoimina, há décadas são utilizadas como monômeros na preparação de polietilenoiminas (PEI) e co-polímeros de larga aplicação industrial ${ }^{17,18}$ (Figura 1).
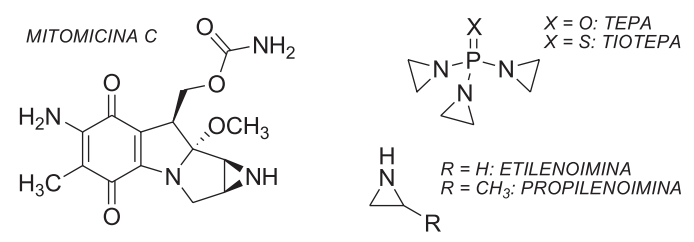

Figura 1. Aziridinas de importância biológica e comercial
Aziridinas também são compostos extremamente versáteis em síntese, sendo empregadas como blocos de construção ${ }^{19,20}$ na preparação de fármacos, substâncias bioativas e produtos naturais (benzodiazepinas, penicilinas e alcalóides, entre outros), bem como ligantes ou auxiliares quirais ${ }^{21,22}$ importantes em síntese assimétrica. $\mathrm{O}$ interesse no comportamento de aziridinas contendo diferentes grupos funcionais e o desenvolvimento de novas aplicações sintéticas objetivando a preparação de heterociclos de estruturas complexas e inéditas estão constantemente presentes na literatura atual. Diversas metodologias para preparação de aziridinas têm sido descritas recentemente, de forma a proporcionar o acesso cada vez mais eficiente a esta importante classe de compostos. Dentre os métodos mais tradicionais, as reações de ciclização intramolecular envolvendo $\beta$-halo- ou $\beta$-sulfonilaminas (Método A, Esquema 1) ainda são bastante empregadas, porém a preparação dos substratos de partida normalmente requer várias etapas reacionais. Por outro lado, a reação de inserção direta de grupos funcionais nitrogenados a um alceno tem sido uma excelente opção sintética para a preparação geral de aziridinas, já que envolve reagentes de fácil acesso e condições reacionais brandas, além de possibilitar a exploração de catálise assimétrica para a

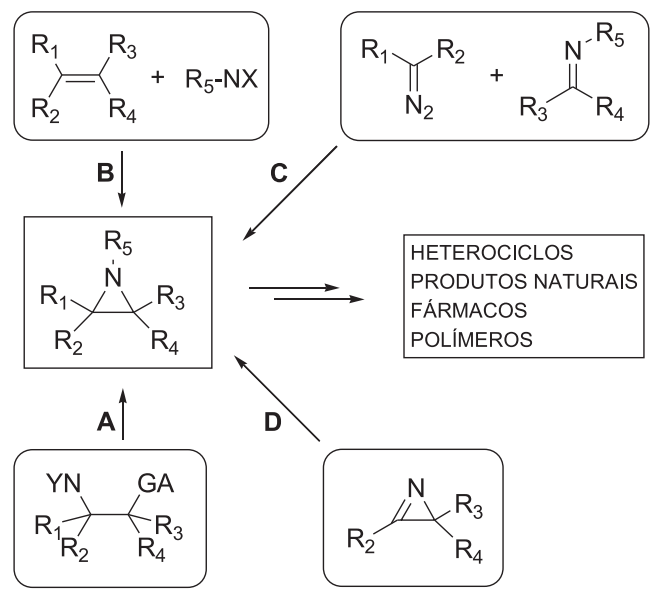

$\mathrm{NX}=\mathrm{NH}_{2}, \mathrm{~N}=\mathrm{IR}, \mathrm{NHOR}, \mathrm{N}-\mathrm{N} \equiv \mathrm{N}, \mathrm{NCl}_{2}, \mathrm{NCINa}, \mathrm{NBrNa}$ $\mathrm{NY}=\mathrm{NH}_{2}, \mathrm{NHR}, \mathrm{N}-\mathrm{N} \equiv \mathrm{N}$

$\mathrm{GA}=\mathrm{Br}, \mathrm{Cl}, \mathrm{OR}$, etc. 
construção de moléculas quirais (Método B, Esquema 1). Uma variação elegante deste último método consiste na inserção de carbenos, metalo-carbenóides ou carbânions a iminas (Método C, Esquema 1), também envolvendo condições reacionais simples e alta seletividade. Finalmente, a utilização de azirinas como análogos insaturados de aziridinas, explorando a reatividade da ligação $\mathrm{C}=\mathrm{N}$ em reações de adição nucleofílica ou cicloadições com dienos, produz aziridinas multifuncionalizadas de difícil acesso por métodos convencionais (Método D, Esquema 1).

Este trabalho tem por finalidade apresentar as estratégias sintéticas mais importantes para preparação de aziridinas funcionalizadas, enfatizando as metodologias desenvolvidas na última década e os aspectos mais relevantes envolvidos em cada transformação, assim como ilustrar algumas aplicações de aziridinas visando a síntese de heterociclos e produtos naturais de interesse biológico e farmacêutico.

\section{AZIRIDINAS A PARTIR DE REAÇÕES DE SUBSTITUIÇÃO INTRAMOLECULAR}

As preparações mais tradicionais de aziridinas envolvem reações de ciclização intramolecular de $\beta$-haloaminas (reação de Gabriel), $\beta$-sulfonilaminas ou $\beta$-aminossulfatos (reação de Wenker), normalmente utilizando alcenos ou aminoálcoois como precursores dos substratos 1,2-difuncionalizados ${ }^{10}$. Exemplos recentes do emprego de $\beta$-haloaminas e derivados podem ser encontrados na preparação da cianoaziridina $\mathbf{1}$, um precursor ${ }^{13}$ de agentes antitumorais, e da bromometilaziridina 2 , um importante intermediário sintético na preparação de heterociclos e aminas funcionalizadas $^{23-26}$ (Esquema 2).

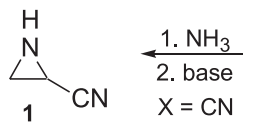

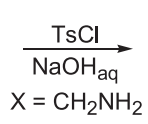

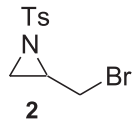

\section{Esquema 2}

A síntese diastereosseletiva de aziridina-2-carboxilatos (3), substratos versáteis na preparação de $\alpha$ - e $\beta$-aminoácidos não-naturais, foi realizada em bons rendimentos e sob condições brandas, a partir da adição de $N, N$-dicloro- $p$-toluenossulfonamida a derivados do ácido cinâmico mediada por triflato de cobre(I), seguida de redução da $\mathrm{N}$-cloroamina formada (4a) utilizando $\mathrm{Na}_{2} \mathrm{SO}_{3}$ aquoso e posterior ciclização da 2-cloro-3-tosilamina resultante (4b) em meio básico ${ }^{27,28}$ (Esquema 3).

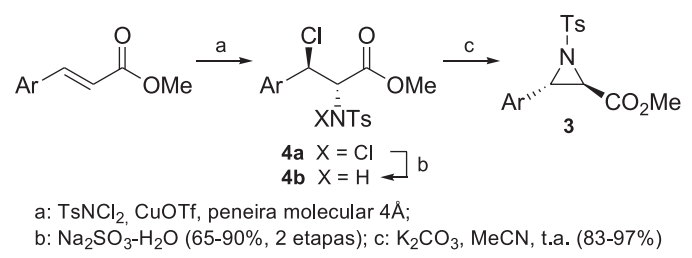

Esquema 3

Já a ciclização a partir de eletrófilos menos reativos normalmente exige condições reacionais mais drásticas. O tratamento da $N$-(2-bromoalil)amina $\mathbf{5}$ com amideto de sódio em amônia líquida forneceu a vinilaziridina $\mathbf{6}$ em alto rendimento, a qual foi posteriormente empregada de maneira elegante ${ }^{29}$ na síntese de biciclos nitrogenados, como a indolizidina 7, a partir de processos em cascata envolvendo o intermediário radicalar 8 (Esquema 4).

A redução de halo-iminas vicinais com hidretos metálicos for-

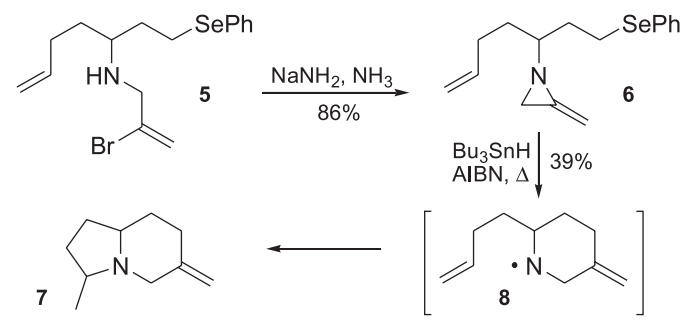

Esquema 4

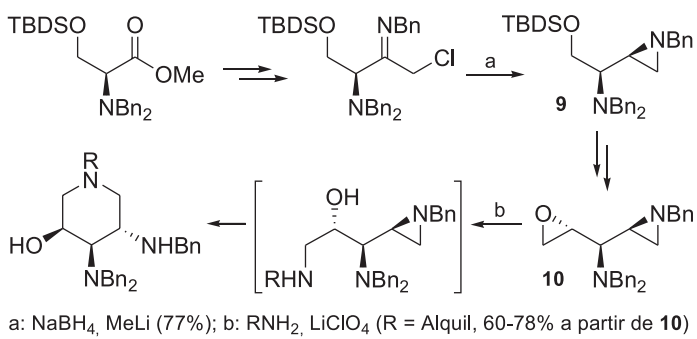

Esquema 5

nece halo-aminas que ciclizam para formar as aziridinas correspondentes nas condições reacionais, sendo uma opção interessante $^{25,26}$ no caso de halo-aminas instáveis ${ }^{30}$ (Esquema 5). Dessa forma, aziridinas multifuncionalizadas $\mathbf{9}$ e $\mathbf{1 0}$ podem ser obtidas a partir de reagentes de fácil acesso e utilizadas como intermediários quirais de relevância sintética.

A transformação de $\beta$-aminoálcoois nas respectivas $\beta$-sulfonilaminas ou $\beta$-aminossulfatos com posterior ciclização para aziridinas é uma alternativa sintética ${ }^{10}$ que vem sendo empregada com sucesso há décadas. Sendo que $\beta$-sulfonilaminas geralmente são espécies instáveis e que seu isolamento causa decréscimo no rendimento e na pureza ótica, aziridinas quirais podem ser obtidas diretamente ${ }^{31-34}$ a partir de $\beta$-aminoálcoois pelo tratamento com cloreto de arilsulfonila em meio básico. Estratégia similar foi empregada na preparação da aziridina 11, utilizada como precursor de azamacrociclos $\mathbf{1 2}$ como modelos que mimetizam metaloenzimas responsáveis pela clivagem de DNA e RNA ${ }^{35}$ (Esquema 6). Entretanto, a preparação de aziridinas contendo grupos funcionais reativos requer estratégias sintéticas que não envolvam condições ácidas ou básicas. A reação de Mitsunobu intramolecular de $\beta$ aminoálcoois vem sendo estudada como uma metodologia direta na obtenção de vinilaziridinas. A abertura do epóxido quiral 13 com amônia (sob microondas) seguida de ciclização do aminoálcool 14 promovida por trifenilfosfina e azodicarboxilato de isopropila (DIAD) fornece a vinilaziridina $\mathbf{1 5} \mathrm{em}$ bons rendimentos e condições brandas ${ }^{36,37}$ (Esquema 7). A vinilaziridina 15 e análogos, como 16, participam em diversas transformações sintéticas valiosas, incluindo a preparação de aminoálcoois com regio- e estereosseletividade invertidas, bem como a transformação para lactamas ${ }^{37,38}$ (Esquema 8).

Apesar de ser uma metodologia importante na obtenção de aziridinas, a reação de Mitsunobu possui algumas desvantagens

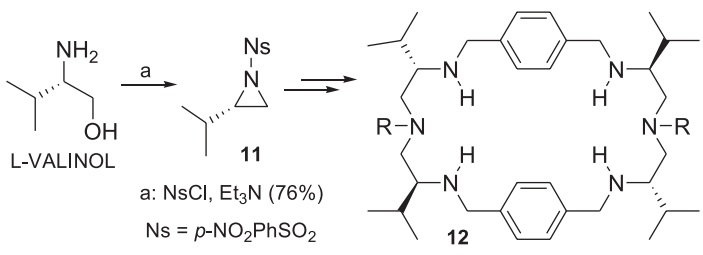

Esquema 6 


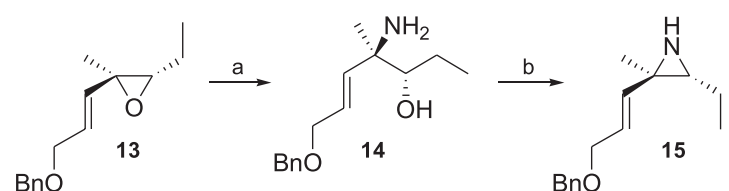

a: $\mathrm{NH}_{4} \mathrm{OH}$, microondas (89\%): b. $\mathrm{PPh}_{3}, \mathrm{DIAD}, \mathrm{THF}, \Delta(80 \%)$

Esquema 7

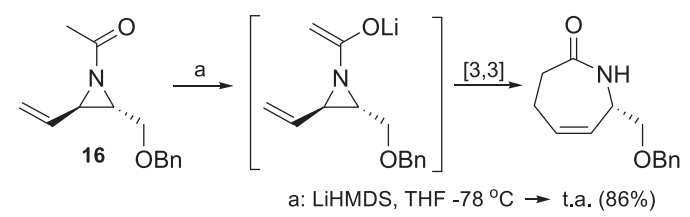

Esquema 8

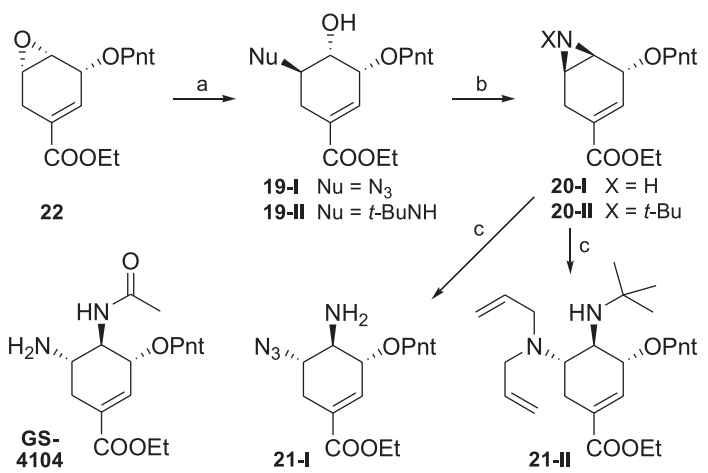

Rota-1 (19-21-I). a: $\mathrm{NaN}_{3}, \mathrm{NH}_{4} \mathrm{Cl}_{(\mathrm{aq})}$; b: $\mathrm{PMe}_{3}$; c: $\mathrm{NaN}_{3}, \mathrm{NH}_{4} \mathrm{Cl}$, DMF (Rendimento global de GS4104, em 4 etapas a partir de 22: $29 \%$ ) Rota-2 (19-21-II). a: $t-\mathrm{BuNH}_{2} \mathrm{MgCl}_{2}$; b: $\mathrm{MsCl}, \mathrm{Et}_{3} \mathrm{~N}$; c: alil $2 \mathrm{NH}, \mathrm{PhSO}_{3} \mathrm{H}$ (Rendimento global de GS4104, em 7 etapas a partir de 22: 61\%)

Esquema 10

\section{AZIRIDINAS A PARTIR DA INSERÇÃO DE NITROGÊNIO EM OLEFINAS} necessidade de utilizar reagentes e aditivos relativamente caros (azodicarboxilatos, por ex.) e que não são incorporados nos produtos finais, levando a uma baixa economia atômica ${ }^{4,5}$. Além disso, o emprego de aminoálcoois como precursores sintéticos pode causar sérias dificuldades experimentais, devido à alta reatividade do grupamento amino frente a eletrófilos. Uma alternativa interessante ${ }^{39}$ para preparação de $\mathrm{NH}$-aziridinas reside na reação entre $\beta$ azidoálcoois e fosfinas, formando intermediários oxazafosforanos cíclicos que sofrem rearranjo para as aziridinas correspondentes ${ }^{40,41}$, com eliminação de óxido de fosfina e sob condições essencialmente neutras. Dessa forma, a reação entre trifenilfosfina e $\beta$-azidoálcoois $\mathbf{1 7}$, convenientemente preparados a partir da abertura de epóxidos ou sulfatos/sulfonatos cíclicos com íon azoteto $\left(\mathrm{N}_{3}^{-}\right)$, produz as respectivas trans-aziridinas 18, utilizadas na síntese de aminoácidos não-naturais ${ }^{42}$ (Esquema 9). Cabe salientar que a utilização de trialquilfosfinas no lugar de trifenilfosfina acarreta vantagens na etapa de purificação, já que os respectivos óxidos de fosfina formados como subprodutos, ao contrário de $\mathrm{Ph}_{3} \mathrm{PO}$, são mais facilmente separados do meio reacional. Dos vários exemplos encontrados na literatura, destaca-se a ciclização do azidoálcool 19-I para a aziridina bicíclica 20-I, um intermediário avançado ${ }^{43}$ na síntese do oseltamivir (GS-4104, Teraflu $\left.{ }^{\circledR}\right)$, inibidor da neuraminidase viral, empregado no tratamento e prevenção do vírus influenza ${ }^{44}$ (Rota-1, Esquema 10). Recentemente, a empresa Roche desenvolveu uma rota sintética mais eficiente para o acesso ao oseltamivir, onde a aziridina $\mathbf{2 0 - I I}$ foi utilizada como intermediário e preparada a partir do aminoálcool correspondente 19-II de modo convencional ${ }^{45}$ (Rota-2, Esquema 10).

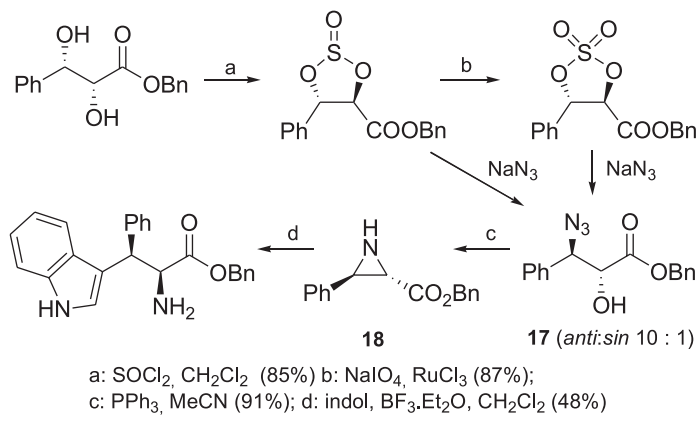

Esquema 9
A reação de inserção de nitrogênio a um alceno constitui-se em um excelente método para preparação de aziridinas, pois normalmente envolve condições reacionais brandas e reagentes de fácil acesso. Diversos tipos de reagentes nitrogenados têm sido empregados na aziridinação de olefinas, destacando-se aminas e derivados $\left(\mathrm{RNH}_{2}\right)$, feniliodinanas (RN=IR'), $N$-sulfoniloxicarbamatos (RNHOR'), azidas $\left(\mathrm{RN}_{3}\right)$ e haloaminas $\left(\mathrm{RNCl}_{2}\right.$ e $\mathrm{RNXNa}$, onde $\left.\mathrm{X}=\mathrm{Cl}, \mathrm{Br}\right)$. Embora várias condições reacionais levem à formação majoritária de aziridinas, mecanismos distintos podem estar atuando em cada transformação e serão brevemente apresentados a seguir.

\section{Feniliodinanas}

A inserção direta de um átomo de nitrogênio a uma olefina geralmente requer a formação inicial de nitrenos ou metalonitrenóides ${ }^{22}$ como espécies altamente eletrofílicas. [N-( $p$ Toluenossulfonil)imino]feniliodinana ( $\mathrm{PhI=NTs)}$ é um precursor de nitreno bastante utilizado para aziridinação de olefinas ${ }^{46,47}$ (Esquema 11). Na presença de olefinas ricas ou deficientes em elétrons, a decomposição de $\mathrm{PhI}=\mathrm{NT}$ s promovida por sais de cobre, como $\mathrm{Cu}(\mathrm{acac})_{2}, \mathrm{Cu}(\mathrm{OTf})_{2}, \mathrm{CuOTf}, \mathrm{CuClO}_{4}$ ou $\mathrm{Cu}(\mathrm{MeCN})_{4} \mathrm{ClO}_{4}$, leva à formação das aziridinas correspondentes em bons rendimentos. A reação apresenta alta estereosseletividade com formação de transaziridinas a partir de (E)-alcenos, mas para olefinas $c i s$ a seletividade depende do seu padrão de substituição e do catalisador utilizado. Estudos envolvendo o mecanismo da reação apoiaram a possibilidade da aziridinação de olefinas não funcionalizadas ocorrer a partir da geração inicial de um nitreno (ou metalo-nitrenóide) com posterior ciclização de maneira concertada ${ }^{48}$ (sem o envolvimento de intermediários iônicos), embora a intermediação de espécies radicalares e a ocorrência de processos mais complexos ${ }^{49}$ tenham sido postuladas. A catálise por $\mathrm{Cu}$ (I) ou $\mathrm{Cu}$ (II) ocorre de maneira análoga e portanto independe do estado de oxidação do sal de cobre

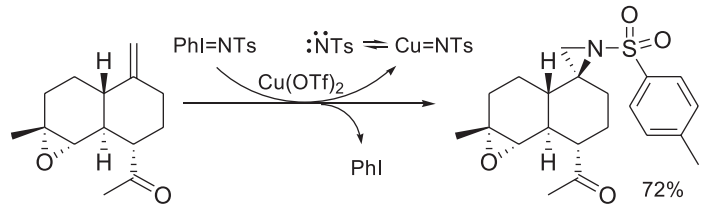


utilizado. Pelo fato de reagentes de iodo(III) serem oxidantes, presume-se que estas reações são catalisadas pelo $\mathrm{Cu}$ (II) formado a partir oxidação de $\mathrm{Cu}(\mathrm{I})$ por $\mathrm{PhI}=\mathrm{NT}$ s.

A utilização de líquidos iônicos ${ }^{50} \operatorname{como}$ meio reacional apresenta grandes vantagens em relação aos solventes orgânicos tradicionais, pois podem ser reutilizados diversas vezes e permitem uma recuperação mais eficiente do catalisador. Um exemplo que pode ser citado é o emprego de $\mathrm{PhI}=\mathrm{NTs}$ e $\mathrm{Cu}(\mathrm{acac})_{2}$ em sais de imidazólio para aziridinação de alquil e aril olefinas com diferentes padrões de substituição $0^{51}$ (Esquema 12).

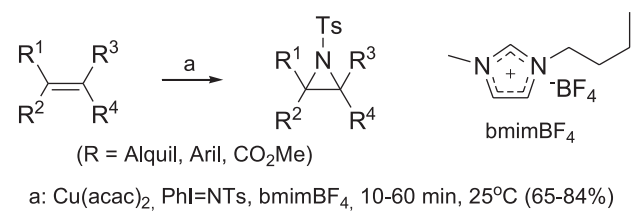

Esquema 12

A versatilidade de $\mathrm{PhI}=\mathrm{NT}$ s como fonte de nitreno pode ser atestada pela preparação enantiosseletiva de aziridinas a partir de catálise assimétrica. Benzaldiminas derivadas de 1,2-diaminociclo-hexano (23) foram utilizadas como ligantes na presença de CuOTf como catalisador, fornecendo aziridinas $\mathbf{2 4} \mathrm{em}$ bons rendimentos e excessos enantioméricos de até $98 \%^{52}$ (Esquema 13).

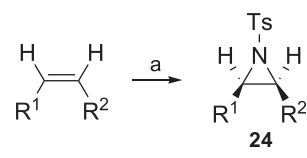

a: CuOTf, $23, \mathrm{Phl}=\mathrm{NTs},-78^{\circ} \mathrm{C}$ $(\mathrm{R} \%=50-79 \% ;$ ee $=30-98 \%)$

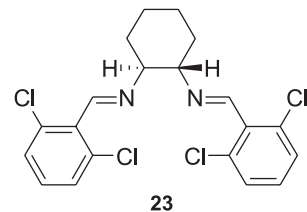

23
Esquema 13

\section{Aminas e derivados}

Apesar do sucesso na aziridinação de alcenos empregando feniliodinana, este reagente requer cuidados especiais na sua preparação e manipulação, limitando uma utilização abrangente. Além disso, dificuldades inerentes à formação de pelo menos 1 equivalente de iodobenzeno como sub-produto da reação restringem ainda mais sua aplicação sintética. Uma alternativa interessante para contornar em parte estes problemas reside na oxidação de reagentes possuindo a função amino com reduzido caráter nucleofílico, como derivados de hidrazidas, carbamatos, sulfonamidas e sulfamatos, que geram espécies nitrogenadas reativas frente a olefinas. A aziridinação de alcenos com hidrazidas cíclicas como $\mathrm{N}$-aminoquinazolinona ou $N$-aminoftalimida utilizando tetraacetato de chumbo como agente oxidante envolve, provavelmente, a formação inicial de intermediários $N$-acetoxilados reativos com posterior adição à insaturação $0^{53}$ (Esquema 14a).

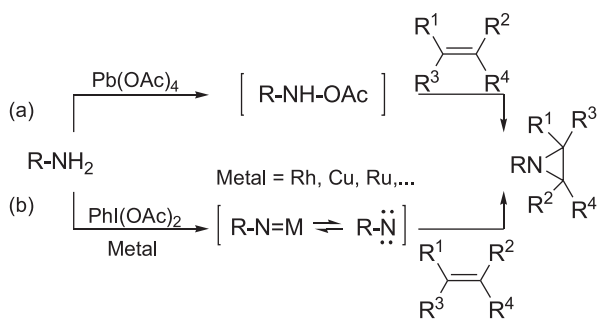

A substituição de $\mathrm{Pb}(\mathrm{OAc})_{4}$ por agentes oxidantes menos tóxicos levou ao desenvolvimento de metodologias mais versáteis para inserção de nitrogênio a alcenos. Esse tipo de reação ocorre na presença de um oxidante brando, como o diacetato de feniliodo(III) (PIDA), e de um aditivo metálico, promovendo a geração e transferência de nitreno para olefinas com formação das aziridinas correspondentes ${ }^{54,55} \mathrm{em}$ bons rendimentos e alta quimiosseletividade (Esquema 14b). A reação com $N$-aminoftalimida (25) mostrou-se bem tolerante para vários grupos funcionais, como compostos carbonílicos, nitrilas, hidroxilas e amidas (Esquema 15).

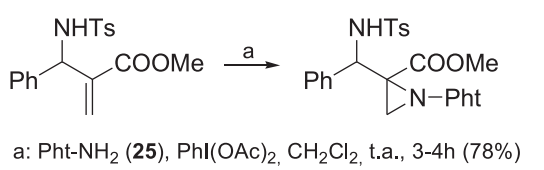<smiles>CCCCN1C(=O)c2ccccc2C1=O</smiles>

\section{Esquema 15}

A simplicidade dessa metodologia foi estendida para sulfonamidas e sulfamatos, precursores de metalo-nitrenóides a partir de catalisadores metálicos ${ }^{56,57}$ de ródio, cobre e rutênio, principalmente. Um exemplo é o uso de tricloroetanossulfamato (26) como fonte de nitrogênio, na presença de $\mathrm{Rh}_{2}\left(\mathrm{CF}_{3} \mathrm{CONH}\right)_{4}$ como catalisador e de $\mathrm{PhI}(\mathrm{OAc})_{2} / \mathrm{MgO}$ como sistema oxidante, para aziridinação de alquil e aril olefinas ${ }^{58}$ (Esquema 16). O mecanismo proposto envolve transferência eletrofílica de Rh-nitreno, levando à formação de aziridinas de maneira estereoespecífica.
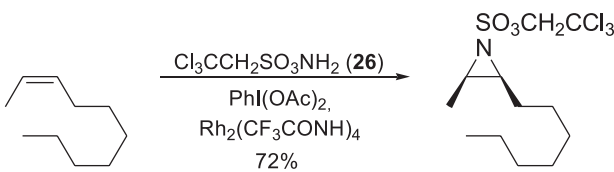

Esquema 16

A síntese assimétrica de aziridinas 27 tem sido estudada ${ }^{59}$ a partir da adição de ligantes bis-oxazolinas quirais $\mathbf{2 8}$ nas condições reacionais típicas (olefina/PIDA/metal), obtendo-se excessos enantioméricos na faixa de 22-80\% (Esquema 17).

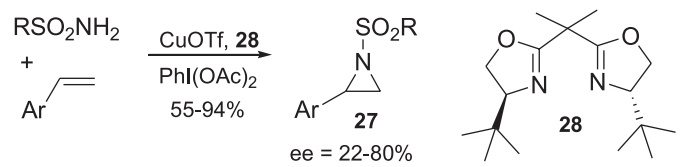

Esquema 17

A reação de inserção de nitrogênio intramolecular em $\omega$ vinilsulfonamidas ${ }^{60}$ e carbamatos ${ }^{61}$ representa o acesso a aziridinas bicíclicas com potencial aplicação sintética. A aziridinação intramolecular de $\omega$-vinilcarbamatos $\mathbf{2 9}$ fornece azatriciclos $\mathbf{3 0}$, que sofrem abertura do anel aziridínico por ataque nucleofílico de álcoois ou aminas com posterior clivagem do núcleo oxazolidinônico por tratamento ácido, fornecendo moléculas polifuncionais com alta diastereosseletividade ${ }^{62}$ (Esquema 18).

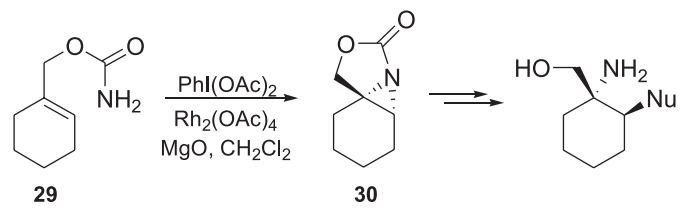


Apesar das vantagens associadas ao emprego de $\mathrm{PhI}(\mathrm{OAc})_{2}$ como oxidante de grupos amino, a reação também apresenta o inconveniente de produzir 1 equivalente de iodobenzeno acompanhando a formação das aziridinas, de maneira similar ao que ocorre com o uso de $\mathrm{PhI}=\mathrm{NT}$. Um método mais limpo emprega a $\mathrm{N}$ aminoftalimida (25) para aziridinação de olefinas, gerando espécies reativas eletroquimicamente na presença de trietilamina e ácido acético. A reação fornece aziridinas com rendimentos entre 42 e $93 \%$, a partir de olefinas possuindo uma diversidade de substituintes doadores e retiradores de elétrons, constituindo-se em uma alternativa vantajosa ao uso de reagentes oxidantes ${ }^{63}$ (Esquema 19).

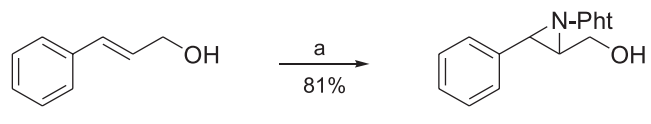

a: $+1,80 \mathrm{~V}$ (vs Ag), Pht- $\mathrm{NH}_{2}$ (25), $\mathrm{CH}_{3} \mathrm{CN}, \mathrm{Et}_{3} \mathrm{~N}, \mathrm{HOAc}$, t.a., 3-4h

\section{Esquema 19}

\section{$N$-Sulfoniloxicarbamatos}

$N$-Sulfoniloxicarbamatos e, mais recentemente, uma combinação ${ }^{64}$ de $N$-fenil-hidroxamato e $\mathrm{NaOH}$, são utilizados como fonte de nitrogênio para aziridinação de olefinas deficientes em elétrons. A reação ocorre via adição do tipo aza-Michael e a reatividade das olefinas é influenciada por seu impedimento estérico. O nosiloxicarbamato de etila ( $\mathrm{NsONHCO}_{2} \mathrm{Et}$; $\mathrm{Ns}=4$-nitrofenilsulfonil) ${ }^{65,66}$ é um reagente eficiente na adição a acrilatos substituídos por grupos retiradores de elétrons $\mathbf{( 3 1 )}$, fornecendo aziridinas multissubstituídas 32 em rendimentos entre 62 e $98 \%$ (Esquema 20).
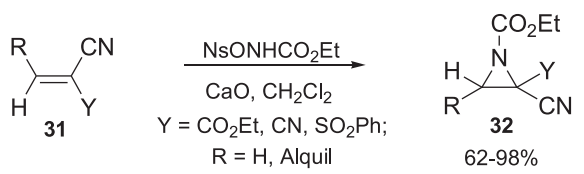

Esquema 20

O nosiloxicarbamato de etila foi utilizado na síntese enantiosseletiva de aziridinas bicíclicas 33, importantes análogos sintéticos de diversos compostos sulfurados de interesse biológico, em combinação com sais quaternários de alcalóides da classe Cinchona (por ex., 34) como catalisadores assimétricos de transferência de fase $^{67}$ (Esquema 21).

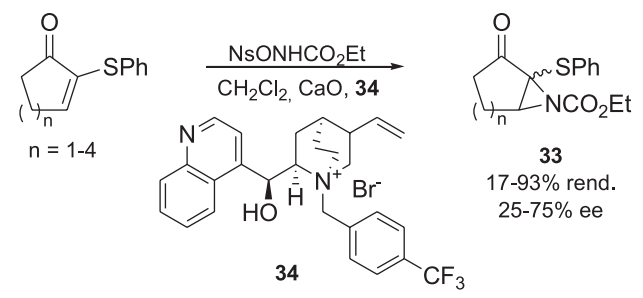

Esquema 21

\section{Azidas}

A decomposição da benzenossulfonilazida $\left(\mathrm{PhSO}_{2} \mathrm{~N}_{3}\right)$ catalisada por cobre gera uma espécie nitrenóide que, na presença de excesso de ciclo-hexeno ${ }^{68}$, fornece ciclo-hexilidenoaziridina (35) como pro- duto majoritário. Entretanto, na ausência de metal e sob aquecimento, azidas participam como dipolos em reações de cicloadição 1,3-dipolar com olefinas ativadas, fornecendo um intermediário [1,2,3]-triazolina 36 que sofre decomposição térmica ou fotoquímica com eliminação de nitrogênio e formação das respectivas aziridinas $^{69,70}$ (Esquema 22). Estereoisômeros endo-endo 37 e exoendo 38 de benzenossulfonilaziridinas ${ }^{71}$ podem ser preparados pela reação entre $p$-toluenossulfonilazida $\left(\mathrm{TsN}_{3}\right)$ e endonorbornenossuccinimidas 39 (Esquema 23). Os rendimentos variam entre 62 e $90 \%$, sendo que a aziridina endo-endo 37 é sempre obtida em maior proporção.

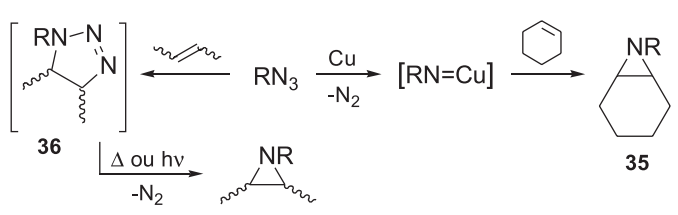

Esquema 22

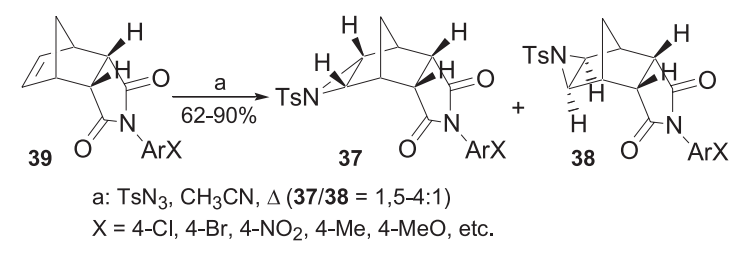

Esquema 23

A preparação de aminoglicosídeos, uma importante classe de derivados de carboidratos, pode ser realizada ${ }^{72}$ a partir da reação do respectivo precursor glicol com uma azida. $\mathrm{O}$ tri- $O$-acetilglucal 40 sofre cicloadição com azidas ricas em elétrons, como a benzilazida, a elevadas temperaturas. A triazolina $\mathbf{4 1}$ gerada pode ser transformada fotoquimicamente na aziridina correspondente $\mathbf{4 2}$, que é semi-estável. Na presença de $\mathrm{Sc}(\mathrm{OTf})_{3}$, esta aziridina pode reagir com nucleófilos, como álcoois e derivados nitrogenados, formando os respectivos mono- e di-aminoglicosídeos 43 estereosseletivamente (Esquema 24).
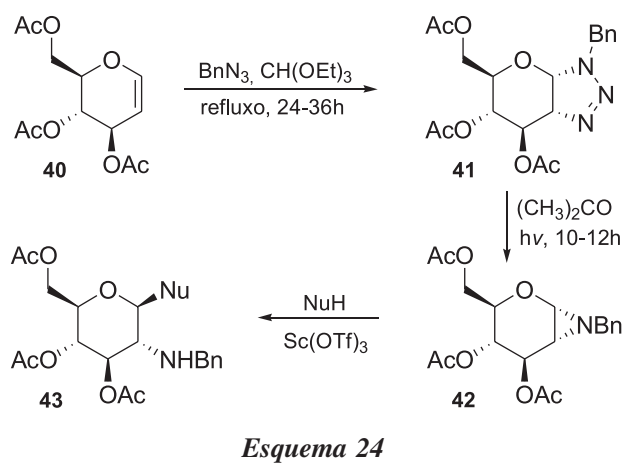

A adição de azidas ricas em elétrons a carbonilas $\alpha, \beta$-insaturadas, promovida por ácido tríflico (TfOH) sob condições brandas, fornece as aziridinas correspondentes $\mathbf{4 4} \mathrm{em}$ bons rendimentos. O mecanismo proposto ${ }^{73}$ para esta conversão passa pelo estado de transição ET, gerado a partir da formação do intermediário aminodiazônio A por adição conjugada, ou pela fragmentação da triazolina $\mathbf{B}$ (Esquema 25). 


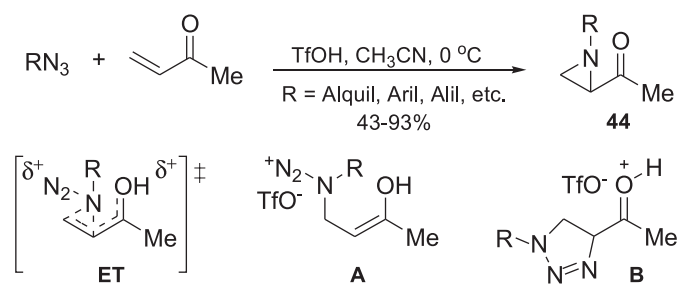

Esquema 25

\section{Haloaminas}

Cloramina-T ( $N$-cloro- $N$-sodio- $p$-toluenossulfonamida ou TsNNaCl, 45) ${ }^{74}$ tem sido amplamente utilizada como reagente precursor de nitrogênio em reações de inserção em olefinas, visto que é um reagente barato e forma apenas $\mathrm{NaCl}$ como sub-produto de reação. $\mathrm{O}$ método geral consiste, basicamente, na reação da olefina com a Cloramina-T anidra ou tri-hidratada na presença de um catalisador, que pode ser metálico ou não (Esquema 26). É importante ressaltar que o uso da Cloramina-T tri-hidratada é mais vantajoso, pelo fato desta ser disponível comercialmente e, ainda, porque a secagem da Cloramina-T é um processo ${ }^{75}$ que envolve risco de explosão.

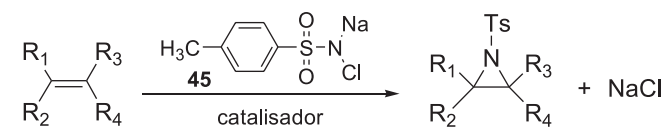

Esquema 26

Diversos sistemas catalíticos têm sido descritos para a reação de aziridinação de olefinas utilizando Cloramina-T como fonte de nitrogênio. A utilização de iodo molecular ou cloreto de cobre(I) na presença de peneira molecular fornece aziridinas em rendimentos variados ${ }^{76,77}(16-91 \%)$, sendo mais eficiente com olefinas dissubstituídas por grupos alquil ou aril. A metodologia desenvolvida por Sharpless e colaboradores ${ }^{78}$ emprega tribrometo de feniltrimetilamônio (PTAB) como catalisador para a aziridinação de olefinas 1,2-dissubstituídas e álcoois alílicos em bons rendimentos, utilizando tanto Cloramina-T anidra quanto tri-hidratada. Estas condições reacionais foram posteriormente estendidas ${ }^{79}$ para a aziridinação de álcoois alílicos cíclicos como uma das etapas de síntese de aminas alílicas. Outros exemplos de catalisadores descritos na literatura para este tipo de reação são: complexos porfirínicos de ferro e peneira molecular para a aziridinação de derivados de estireno ${ }^{80}$ (rendimentos de 32-60\%); $\mathrm{N}$-bromosuccinimida na aziridinação de alquil e aril olefinas, bem como de álcoois e brometos alílicos e de ésteres e cetonas $\alpha, \beta$-insaturados ${ }^{81}$ (rendimentos entre 50 e $88 \%$ ); peróxido de hidrogênio/brometo de hidrogênio aquoso, fornecendo aril- e alquil aziridinas ${ }^{82}$ em rendimentos de 45-92\%; e ácido fosfomolibídico ${ }^{83,84}$ (PMA) na presença de peneira molecular sob condições de catálise por transferência de fase. Alguns autores sugerem que a geração de nitrenos como intermediários reativos ocorre pela decomposição de $\mathbf{4 5}$ catalisada por metais. Entretanto, o mecanismo mais aceito para as reações promovidas por reagentes halogenados envolve a formação inicial de espécies iônicas oriundas da adição eletrofílica de íon halônio (" $\mathrm{X}^{+}$") à dupla ligação $\mathrm{C}=\mathrm{C}$, seguido de ataque nucleofílico por Ts $\mathrm{NCl}^{-}$e posterior ciclização para a aziridina correspondente, regenerando o catalisador ("Cat-X") ${ }^{81,82}$ (Esquema 27).

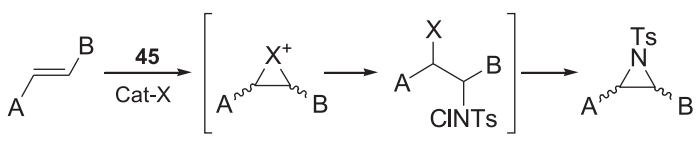

Esquema 27

Análogos da Cloramina-T também têm sido utilizados para aziridinação de olefinas. Bromamina-T ( $N$-bromo- $N$-sodio- $p$ toluenossulfonamida ou $\mathrm{TsNNaBr}$ ) tem se apresentado como melhor agente doador de nitreno em relação à Cloramina-T, na aziridinação de diferentes alquil e aril olefinas ${ }^{85}$ sob catálise de $\mathrm{CuCl}$ ou metalo-porfirinas. Já a catálise por $\mathrm{PdCl}_{2}$ se mostrou mais eficiente ${ }^{86}$ para aziridinação de olefinas deficientes de elétrons, com rendimentos entre 20 e $81 \%$. O emprego de $N, N$-dicloro- $p$-toluenossulfonamida (46) para aziridinação de ésteres e cetonas $\alpha, \beta$ insaturados catalisada por CuOTf na presença de peneira molecular foi recentemente relatado. $\mathrm{O}$ tratamento subseqüente com $\mathrm{Na}_{2} \mathrm{SO}_{3}$ aquoso e base fornece aziridinas funcionalizadas com rendimentos entre 53 e $86 \%$ e seletividade trans $^{87}$ (Esquema 28). O mecanismo ocorre pela formação inicial de produtos de amino-halogenação seguido por reação de ciclização intramolecular in situ.

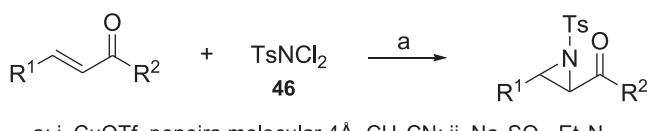

Esquema 28

\section{AZIRIDINAS A PARTIR DA INSERÇÃO DE CARBONO EM IMINAS}

A reação entre compostos diazo e iminas tem sido cada vez mais empregada ${ }^{20}$ como uma metodologia simples para a obtenção de aziridinas com alta seletividade. Diazometano, diazoacetato de etila (EDA) e trimetilsilildiazometano (TMSD) são os reagentes mais estudados, embora as condições reacionais variem consideravelmente para cada caso. Considerando que a reatividade de EDA frente a iminas é normalmente baixa, existe a necessidade de se empregar um catalisador de modo a conduzir adequadamente a formação de aziridinas. Diversos tipos de ácidos de Lewis ${ }^{88-93}$ já foram descritos como catalisadores para essa reação, entre eles $\mathrm{BF}_{3}, \mathrm{AlCl}_{3}$, $\mathrm{TiCl}_{4}, \mathrm{ZnI}_{2}, \mathrm{InCl}_{3}$ e triflatos como $\mathrm{Zn}(\mathrm{OTf})_{2}, \mathrm{Yb}(\mathrm{OTf})_{3}$ e La(OTf), incluindo versões assimétricas ${ }^{94}$ (Esquema 29). Ácidos de Bronsted, como ácido clorídrico, trifluoroacético ou trifluorometanossulfônico, também se mostraram eficientes ${ }^{95}$ para este tipo de transformação. Acredita-se que a função do catalisador ácido seja a de coordenarse com o nitrogênio da imina de forma a aumentar a eletrofilicidade do carbono imínico frente ao ataque nucleofílico de EDA, gerando um intermediário $\mathbf{4 7}$ que sofre posterior ciclização antiperiplanar formando cis-aziridinas 48 seletivamente ${ }^{22,88-90}$ (Esquema 30a). Já a reação direta de EDA com iminas à temperatura ambiente utilizando líquidos iônicos como solvente ocorre sem a necessidade de catalisadores ácidos, produzindo de maneira elegante ${ }^{96}$ as aziridinas correspondentes em bons rendimentos e elevada seletividade cis.

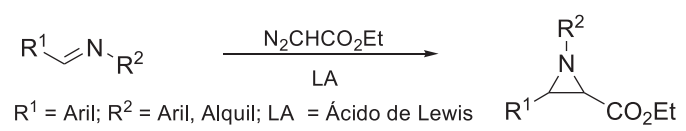

Esquema 29 


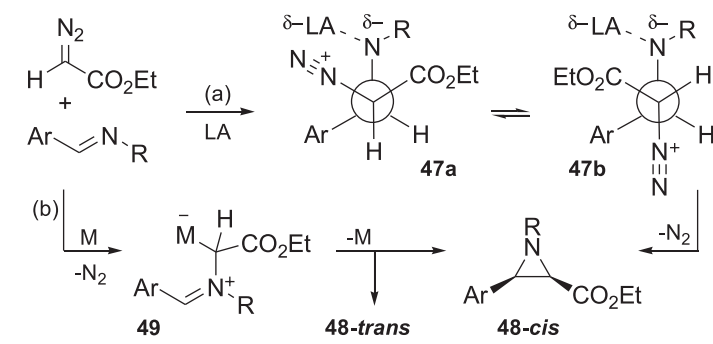

Esquema 30

Por outro lado, compostos diazo sofrem eliminação de $\mathrm{N}_{2}$ na presença de complexos de metais de transição, dando origem a espécies metalocarbenóides reativas frente ao ataque nucleofílico de iminas, formando o intermediário $49 \mathrm{com}$ posterior ciclização para as aziridinas correspondentes ${ }^{89}$ (Esquema 30b). A descoberta de que complexos de ródio(II) catalisam a decomposição de diversos compostos diazo com posterior inserção sobre iminas ou aná$\log 0 \mathrm{~s}^{97-99}$ expandiu ainda mais as possibilidades desta transformação, permitindo a síntese de trans-aziridinas ${ }^{100}$ e de derivados multifuncionalizados $\mathbf{5 0}$ sob condições brandas ${ }^{98}$ (Esquema 31 ).

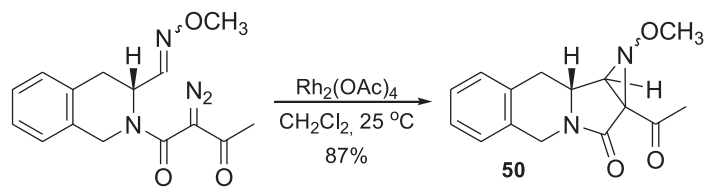

Esquema 31

Já a utilização de TMSD em reações com $N$-sulfoniliminas $\mathbf{5 1}$ na ausência de catalisador tem se apresentado como uma alternativa conveniente para o acesso a aziridinas. As $C$-sililaziridinas $\mathbf{5 2}$ formadas apresentam elevado potencial sintético devido à facilidade de substituição do grupo silil por diferentes eletrófilos, com retenção da configuração, além da possibilidade de abertura regiosseletiva do anel promovida por agentes nucleofílicos ${ }^{101-103}$ (Esquema 32). Uma variante desta reação foi empregada na síntese enantiosseletiva ${ }^{104}$ de aziridinas, a partir de $\alpha$-iminoésteres $N$-substituídos e TMSD catalisada por complexos de cobre(I) e ligantes quirais.

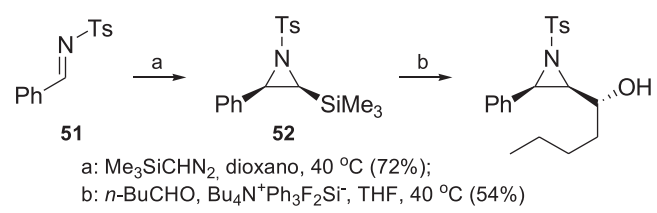

Esquema 32

2-Fosfonoaziridinas são importantes intermediários sintéticos empregados na síntese de aminofosfonatos de relevância biológica. Estes interessantes compostos podem ser preparados pela reação entre 1-fosfono-2-aza-1,3-dienos 53 e compostos diazo (diazometano, TMSD ou EDA), fornecendo as aziridinas correspondentes 54-56 com rendimentos entre 29 e $57 \%$ e seletividade cis. É importante ressaltar que a adição de carbeno ocorre regioespecificamente no carbono imino eletrofílico próximo ao grupo fosfonato retirador de elétrons ${ }^{105}$ (Esquema 33).

Outras fontes de carbono diferentes de compostos diazo incluem sais derivados de tetra-hidrotiofeno e brometo de alila. A preparação de vinil aziridinas $\mathbf{5 7}$ ocorre pela reação entre $N$-sulfoniliminas $\mathbf{5 8}$ e brometo de $S$-alil tetra-hidrotiofeno $\mathbf{5 9}$ na presença de base, com

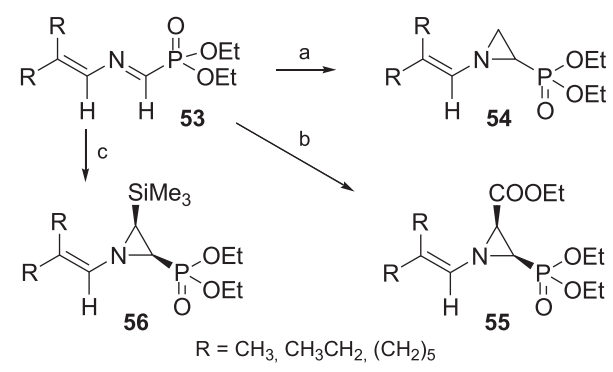

a: $\mathrm{CH}_{2} \mathrm{~N}_{2}, \mathrm{Et}_{2} \mathrm{O}$; b: $\mathrm{EDA}, \mathrm{Yb}(\mathrm{OTf})_{3}, \mathrm{CH}_{2} \mathrm{Cl}_{2}$; c: TMSD, tolueno

Esquema 33

seletividade moderada em favor dos isômeros trans $^{106}$ (Esquema 34).

A inserção formal de um átomo de carbono a uma ligação $\mathrm{C}=\mathrm{N}$ pode ser obtida a partir de uma concepção diferente, utilizando a reação entre iminas quirais 60 e halo-enolatos 61 gerados ${ }^{107}$ a partir do tratamento de $\alpha$-bromoésteres com uma base forte a $-78{ }^{\circ} \mathrm{C}$. A formação de aziridinas $\mathbf{6 2}$ possivelmente envolve um intermediário aberto $\mathbf{6 3}$ que precede a ciclização intramolecular, fornecendo o isômero cis com excesso diastereomérico de 66\% (Esquema 35).

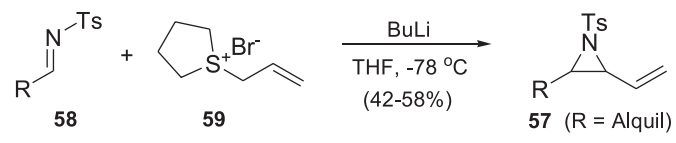

Esquema 34

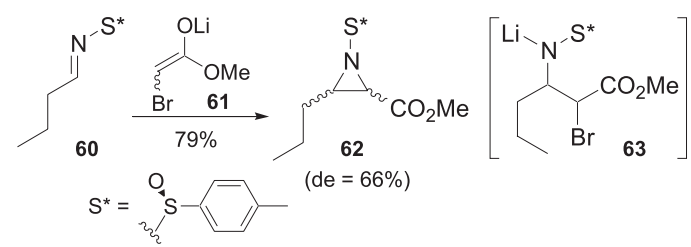

Esquema 35

\section{AZIRIDINAS A PARTIR DE AZIRINAS}

Azirinas são blocos de construção importantes ${ }^{108-110}$ para a síntese de diversos heterociclos, incluindo ${ }^{110-112}$ aziridinas multifuncionalizadas, a partir da adição de nucleófilos ao carbono imino ou da cicloadição com dienos. Diversas metodologias bem estabelecidas para o acesso a azirinas têm sido descritas ${ }^{110}$ e incluem reações intramoleculares de iminas $\mathrm{N}$-funcionalizadas, vinil azidas e isoxazóis, ou ainda reações de inserção entre carbenos e nitrilas ou nitrenos e alcinos.

Reações nucleofílicas sobre azirinas são estereosseletivas e incluem a redução da ligação $\mathrm{C}=\mathrm{N}$ por hidretos de metal, ocorrendo preferencialmente na face menos impedida do anel com formação de aziridinas trans. A adição de grupos alquílicos secundários e terciários à azirinacarboxilato $\mathbf{6 4}$, provenientes da reação entre iodetos de alquila e trietilborano, leva à formação das aziridinas correspondentes $\mathbf{6 5}$ em bons rendimentos e elevada regio- e diastereosseletividade ${ }^{113}$ (Esquema 36).

Aziridinas quirais funcionalizadas $\mathbf{6 6}$ são preparadas pela reação das respectivas azirinas $\mathbf{6 7} \mathrm{com}$ diversos heterociclos aromáticos nitrogenados ${ }^{114}$ (Esquema 37). Os diastereoisômeros trans são obtidos majoritariamente, apresentando razões diastereoméricas entre 4:1 e 5:1. Entretanto, a adição de reagentes de Grignard à azirina-2carboxilato quiral 68 fornece aziridinas 69 oriundas do ataque $\sin$ ao 
grupo éster, como conseqüência ${ }^{115}$ da pré-quelação do grupo carboxilato com o magnésio. A subseqüente hidrogenação catalítica da aziridina-2carboxilato 69 fornece em altos excessos enantioméricos os $\beta$ aminoácidos quaternários 70, uma classe de compostos que exibe importantes propriedades biológicas ${ }^{107}$ (Esquema 38).

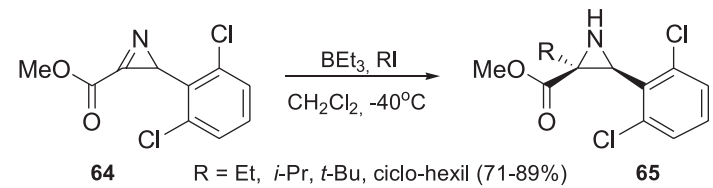

Esquema 36

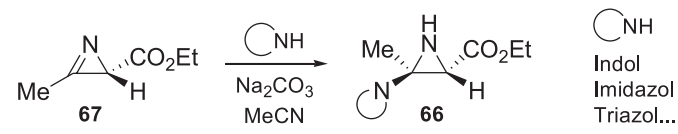

Esquema 37

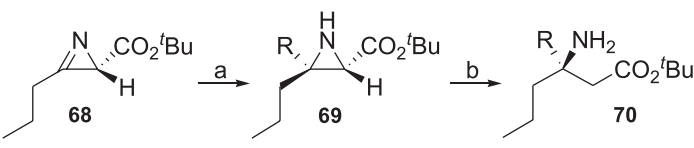

a: $\mathrm{RMgBr}$, THF, $-78{ }^{\circ} \mathrm{C}(73-93 \%)$; b: Ra-Ni, $\mathrm{H}_{2}$, EtOH ( $R$ = Alquil: $71-86 \%,>92 \%$ ee)

Esquema 38

As reações de cicloadição com dienos nas quais azirinas participam como heterodienófilos (aza-Diels-Alder) constituem um método interessante de preparação de aziridinas bicíclicas. O tratamento de azirinas derivadas de carboxamidas $\mathbf{7 1}$ com dienos à temperatura ambiente leva à obtenção ${ }^{116}$ dos respectivos adutos de cicloadição 72 e 73 com rendimentos de 31 a 42\% (Esquema 39). Já a reação entre ciclopentadieno e a azirina quiral $\mathbf{7 1}$ derivada da bis[(S)-1feniletil]amina foi completamente não seletiva, fornecendo uma mistura equimolar de diastereoisômeros com rendimento de 53\%.

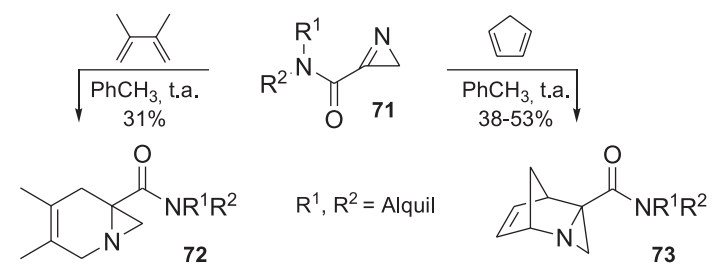

\section{Esquema 39}

Diversas azirinas têm sido utilizadas em reações com diferentes dienos, normalmente ricos em elétrons, formando os respectivos produtos de cicloadição ${ }^{111,117}$ em bons rendimentos. As reações de cicloadição catalisadas por ácidos de Lewis na presença de ligantes quirais forneceram cicloadutos em rendimentos e excessos enantioméricos moderados. Por outro lado, o emprego de azirinas possuindo auxiliares quirais $\mathbf{7 4}$ mostrou-se eficiente, fornecendo aziridinas 75 em excelentes rendimentos e elevada pureza óptica, dependendo das condições reacionais empregadas ${ }^{118}$ (Esquema 40).

Anéis contendo 2-oxocarbonilaziridinas $\mathbf{7 6}$ foram obtidos com excelente diastereosseletividade pela cicloadição do tipo heteroDiels-Alder entre uma azirina eletrofílica (77) e 2-azadienos subs-

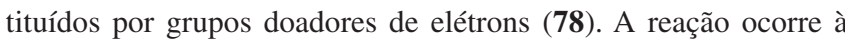
temperatura ambiente na ausência de catalisador, fornecendo os
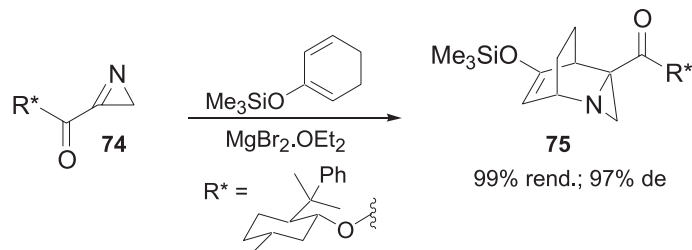

$99 \%$ rend.; $97 \%$ de produtos observados em rendimentos variados ${ }^{119}$ (Esquema 41).

As azirinas têm sido exploradas em reações de cicloadição 1,3dipolar visando a síntese de novos heterociclos. Por exemplo, a bromoazirina $\mathbf{7 9}$ pode reagir como dipolarófilo com o ilídeo azometino 80, gerado a partir da decomposição térmica da aziridina correspondente 81, para dar 2,5-difenilpirimidina-4,6-dicarboxilato 82 em 12\% de rendimento, passando pela aziridina $\mathbf{8 3}$ como intermediário de cicloadição ${ }^{120}$ (Esquema 42).

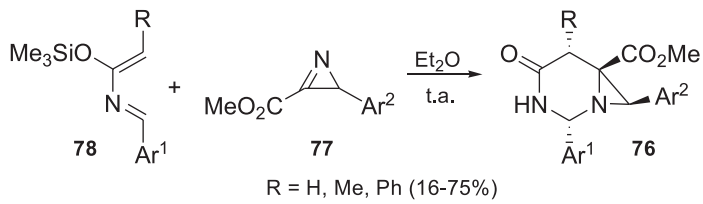

Esquema 41

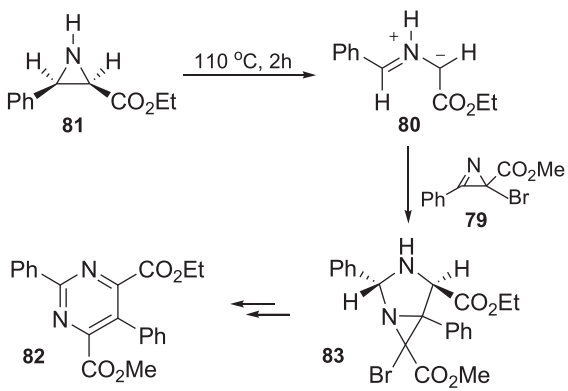

Esquema 42

\section{CONCLUSÃO}

O desenvolvimento de métodos preparativos simples e eficientes na busca por aziridinas possuindo propriedades químicas, físicas e biológicas de interesse científico e tecnológico vem contribuindo significativamente para o reconhecimento destes azaheterociclos como uma importante classe de compostos. As metodologias mais recentes ${ }^{121-131}$ de preparação de aziridinas não levam em conta apenas a sua obtenção em altos rendimentos e seletividade, mas também a necessidade de se empregar reagentes mais acessíveis e gerar quantidades reduzidas de sub-produtos tóxicos. Avanços na síntese assimétrica de aziridinas vêm permitindo um maior entendimento dos parâmetros necessários para a obtenção destes blocos de construção quirais com alta pureza óptica e economia atômica. A combinação peculiar de estabilidade e reatividade química confere às aziridinas uma alta versatilidade em transformações sintéticas subseqüentes. A abertura regiosseletiva do anel com a possibilidade de introdução de dois centros estereogênicos adjacentes são atributos únicos da reatividade de aziridinas, uma classe de intermediários sintéticos que, de maneira similar aos epóxidos, merece um lugar de destaque na química orgânica moderna. 


\section{AGRADECIMENTOS}

Às agências de fomento CAPES, CNPq e FAPESC (Fundação de Amparo à Pesquisa de Santa Catarina) pelas bolsas de estudo e pelo apoio financeiro.

\section{REFERÊNCIAS}

1. Rostovtsev, V. V.; Green, L. G.; Fokin, V. V.; Sharpless, K. B.; Angew. Chem., Int. Ed. 2002, 41, 2596.

2. Himo, F.; Lovell, T.; Hilgraf, R.; Rostovtsev, V. V.; Noodleman, L.; Sharpless, K. B.; Fokin, V. V.; J. Am. Chem. Soc. 2005, 127, 210.

3. Sartori, G.; Ballini, R.; Bigi, F.; Bosica, G.; Maggi, R.; Righi, P.; Chem. Rev. 2004, 104, 199.

4. Anastas, P. T.; Kirchhoff, M. M.; Acc. Chem. Res. 2002, 35, 686.

5. da Silva, F. M.; de Lacerda, P. S. B.; Jones Jr, J.; Quim. Nova 2005, 28, 103.

6. Prado, A. G. S.; Quim. Nova 2003, 26, 738.

7. Padwa, A.; Murphree, S. Em Progress in Heterocyclic Chemistry; Grible, G. W.; Joule, J. A., eds.; Pergamon: Amsterdam, 2004, vol. 16, cap. 3, p. 71-78.

8. Padwa, A.; Woolhouse, A. D. Em Comprehensive Heterocyclic Chemistry; Katritzky, A. R.; Rees, C. W.; Lwowski, W., eds.; Pergamon Press: Oxford, 1984, vol. 7, p. 47-93.

9. Deyrup, J. A. Em The Chemistry of Heterocyclic Compounds; Hassner, A., ed.; Wiley: New York, 1983, vol. 42, part 1, p. 1-214.

10. Dermer, O. C.; Ham, G. E.; Ethyleneimine and Other Aziridines, Academic Press: New York, 1969.

11. Papaioannou, N.; Evans, C. A.; Blank, J. T.; Miller, S. J.; Org. Lett. 2001, 3, 2879.

12. Schirmeister, T.; Peric, M.; Bioorg. Med. Chem. 2000, 8, 1281.

13. Iyengar, B. S.; Dorr, R. T.; Alberts, D. S.; Hersh, E. M.; Salmon, S. E.; Remers, W. A.; J. Med. Chem. 1999, 42, 510.

14. Lewis, D. F. V.; Xenobiotica 1989, 19, 341

15. van de Grampel, J. C.; Coord. Chem. Rev. 1992, 112, 247.

16. Dahlman, D. L.; Kadaba, P. K.; Pestic. Sci. 1988, 22, 71.

17. Roark, D. N.; McKusick, B. C. Em Ullmann's Encyclopedia of Industrial Chemistry; Gerhartz, W., ed.; VCH; $5^{\text {th }}$ ed.; 1985, vol. A3, p. 239-243.

18. Kobayashi, S.; Prog. Polym. Sci. 1990, 15, 751.

19. Hu, X. E.; Tetrahedron 2004, 60, 2701.

20. Müller, P.; Fruit, C.; Chem. Rev. 2003, 103, 2905.

21. Tanner, D.; Angew. Chem., Int. Ed. 1994, 33, 599.

22. McCoull, W.; Davis, F. A.; Synthesis 2000, 1347.

23. D'hooghe, M.; van Brabandt, W.; De Kimpe, N.; J. Org. Chem. 2004, 69, 2703.

24. D'hooghe, M.; Rottiers, M.; Kerkaert, I.; De Kimpe, N.; Tetrahedron 2005, 61, 8746; D’hooghe, M.; Kerkaert, I.; Rottiers, M.; De Kimpe, N.; Tetrahedron 2004, 60, 3637.

25. Tehrani, K. A.; Van, T. N.; Karikomi, M.; Rottiers, M.; De Kimpe, N.; Tetrahedron 2002, 58, 7145.

26. D'hooghe, M.; Rottiers, M.; Jolie, R.; De Kimpe, N.; Synlett 2005, 931

27. Li, G.; Wei, H.-X.; Kim, S. H.; Neighbors, M.; Org. Lett. 1999, 1, 395.

28. Chen, D.; Kim, S. H.; Hodges, B.; Li, G.; Arkivoc 2003, 12, 56.

29. Prévost, N.; Shipman, M.; Tetrahedron 2002, 58, 7165.

30. Concellón, J. M.; Riego, E.; Rivero, I. A.; Ochoa, A.; J. Org. Chem. 2004, $69,6244$.

31. Alonso, D. A.; Andersson, P. G.; J. Org. Chem. 1998, 63, 9455.

32. Bieber, L. W.; Araújo, M. C. F.; Molecules 2002, 7, 902.

33. Cox, P.; Craig, D.; Ioannidis, S.; Rahn, V. S.; Tetrahedron Lett. 2005, 46, 4687.

34. Braga, A. L.; Paixão, M. W.; Marin, G.; Synlett 2005, 1675.

35. Kim, B. M.; So, S. M.; Choi, H. J.; Org. Lett. 2002, 4, 949.

36. Olofsson, B.; Khamrai, U.; Somfai, P.; Org. Lett. $2000,2,4087$.

37. Olofsson, B.; Somfai, P.; J. Org. Chem. 2002, 67, 8574.

38. Lindström, U. F.; Somfai, P.; Synthesis 1998, 109.

39. Gololobov, Y. G.; Kasukhin, L. F.; Tetrahedron 1992, 48, 1353.

40. Mordini, A.; Russo, F.; Valacchi, M.; Zani, L.; Degl'Innocenti, A.; Reginato, G.; Tetrahedron 2002, 58, 7153.

41. Åhman, J.; Jarevång, T.; Somfai, P.; J. Org. Chem. 1996, 61, 8148.

42. Xiong, C.; Wang, W.; Cai, C.; Hruby, V. J.; J. Org. Chem. 2002, 67, 1399.

43. Rohloff, J. C.; Kent, K. M.; Postich, M. J.; Becker, M. W.; Chapman, H. H.; Kelly, D. E.; Lew, W.; Louie, M. S.; McGee, L. R.; Prisbe, E. J.; Schultze, L. M.; Yu, R. H.; Zhang, L.; J. Org. Chem. 1998, 63, 4545.

44. de Fátima, A.; Baptistella, L. H. B.; Pilli, R. A.; Modolo, L. V.; Quim. Nova 2005, 28, 306 .
45. Harrington, P. J.; Brown, J. D.; Foderaro, T.; Hughes, R. C.; Org. Process Res. Dev. 2004, 8, 86.

46. Cunha, R. L. O. R.; Diego, D. G.; Simonelli, F.; Comasseto, J. V.; Tetrahedron Lett. 2005, 46, 2539.

47. White, R. D.; Keaney, G. F.; Slown, C. D.; Wood, J. L.; Org. Lett. 2004, 6,1123 .

48. Evans, D. A.; Faul, M. M.; Bilodeau, M. T.; J. Am. Chem. Soc. 1994, 116, 2742.

49. Li, Z.; Quan, R. W.; Jacobsen, E. N.; J. Am. Chem. Soc. 1995, 117, 5889.

50. Dupont, J.; Souza, R. F.; Suarez, P. A. Z..; Chem. Rev. 2002, 102, 3667.

51. Kantam, M. L.; Neeraja, V.; Kavita, B.; Haritha, Y.; Synlett 2004, 525.

52. Li, Z.; Conser, K. R.; Jacobsen, E. N.; J. Am. Chem. Soc. 1993, 115, 5326.

53. Atkinson, R. S.; Grimshire, M. J.; Kelly, B. J.; Tetrahedron 1989, 45, 2875; Atkinson, R. S.; Draycott, R. D.; Hirst, D. J.; Parratt, M. J.; Raynham, T. M.; Tetrahedron Lett. 2002, 43, 2083.

54. Krasnova, L. B.; Hili, R. M.; Chernoloz, O. V.; Yudin, A. K.; Arkivoc 2005, $4,26$.

55. Li, J.; Liang, J.-L.; Chan, P. W. H.; Che, C.-M.; Tetrahedron Lett. 2004, 45, 2685.

56. Keaney, G. F.; Wood, J. L.; Tetrahedron Lett. 2005, 46, 4031

57. Zhou, Z.-W.; Zhao, Y.-C.; Yue, Y.; Wu, J.; Yang, M.; Yu, X.-Q.; Arkivoc $\mathbf{2 0 0 5}, 1,130$.

58. Guthikonda, K.; Du Bois, J.; J. Am. Chem. Soc. 2002, 124, 13672.

59. Kwong, H.-L.; Liu, D.; Chan, K. Y.; Lee, C. S.; Huang, K.-H.; Che, C.M.; Tetrahedron Lett. 2004, 45, 3965.

60. Liang, J.-L.; Yuan, S.-X.; Huang, J.-S.; Che, C.-M.; J. Org. Chem. 2004, $69,3610$.

61. Padwa, A.; Stengel, T.; Org. Lett. 2002, 4, 2137.

62. Padwa, A.; Flick, A. C.; Leverett, C. A.; Stengel, T.; J. Org. Chem. 2004, 69, 6377.

63. Siu, T.; Yudin, A. K.; J. Am. Chem. Soc. 2002, 124, 530

64. Murugan, E.; Siva, A.; Synthesis 2005, 2022.

65. Fioravanti, S.; Morreale, A.; Pellacani, L.; Tardella, P. A.; Synlett 2004, 1083.

66. Fioravanti, S.; Morreale, A.; Pellacani, L.; Tardella, P. A.; Synthesis 2001, 1975.

67. Fioravanti, S.; Mascia, M. G.; Pellacani, L.; Tardella, P. A.; Tetrahedron 2004, 60, 8073.

68. Kwart, H.; Khan, A. A.; J. Am. Chem. Soc. 1967, 89, 1951.

69. Vogel, P.; Fattori, D.; Gasparini, F.; Drian, C. L.; Synlett 1990, 173.

70. Molteni, G.; Del Buttero, P.; Tetrahedron 2005, 61, 4983.

71. Andrade, E. S.; Nunes, R. J.; Uieara, M.; Synth. Commun. 2004, 34, 3073.

72. Dahl, R. S.; Finney, N. S.; J. Am. Chem. Soc. 2004, 126, 8356.

73. Mahoney, J. M.; Smith, C. R.; Johnston, J. N.; J. Am. Chem. Soc. 2005, 127, 1354.

74. Campbell, M. M.; Johnson, G.; Chem. Rev. 1978, 78, 65.

75. Sarpless, K. B.; Hori, T.; Truesdale, L. K.; Dietrich, C. O.; J. Am. Chem. Soc. 1976, 98, 269.

76. Ando, T.; Minakata, S.; Ryu, I.; Komatsu, M.; Tetrahedron Lett. 1998, 39, 309.

77. Ando, T.; Kano, D.; Minakata, S.; Ryu, I.; Komatsu, M.; Tetrahedron 1998, $54,13485$.

78. Jeong, J. U.; Tao, B.; Sagasser, I.; Henniges, H.; Sharpless, K. B.; J. Am. Chem. Soc. 1998, 120, 6844.

79. Rosser, C. M.; Coote, S. C.; Kirby, J. P.; O’Brien, P.; Caine, D.; Org. Lett. 2004, 6, 4817

80. Simkhovich, L.; Gross, Z.; Tetrahedron Lett. 2001, 42, 8089.

81. Thakur, V. V.; Sudalai, A.; Tetrahedron Lett. 2003, 44, 989.

82. Jain, S. L.; Sharma, V. B.; Sain, B.; Tetrahedron Lett. 2004, 45, 8731.

83. Kumar, G. D. K.; Baskaran, S.; Synlett 2004, 1719.

84. Kumar, G. D. K.; Baskaran, S.; Chem. Commun. 2004, 1026.

85. Vyas, R.; Gao, G.-Y.; Harden, J. D.; Zhang, X. P.; Org. Lett. 2004, 6, 1907; Chanda, B. M.; Vyas, R.; Bedekar, A. V.; J. Org. Chem. 2001, 66, 30.

86. Antunes, A. M. M.; Marto, S. J. L.; Branco, P. S.; Prabhakar, S.; Lobo, A. M.; Chem. Commun. 2001, 405.

87. Chen, D.; Timmons, C.; Guo, L.; Xu, X.; Li, G.; Synthesis 2004, 2479.

88. Casarrubios, L.; Pérez, J. A.; Brookhart, M.; Templeton, J. L.; J. Org. Chem. 1996, 61, 8358 .

89. Rasmussen, K. G.; Jorgensen, K. A.; J. Chem. Soc., Perkin Trans. 1 1997, 1287.

90. Bartnik, R.; Mloston, G.; Synthesis 1983, 924.

91. Sengupta, S.; Mondal, S.; Tetrahedron Lett. 2000, 41, 6245.

92. Xie, W.; Fang, J.; Li, J.; Wang, P. G.; Tetrahedron 1999, 55, 12929.

93. Rowlands, G. J.; Barnes, W. K.; Tetrahedron Lett. 2004, 45, 5347.

94. Antilla, J. C.; Wulff, W. D.; J. Am. Chem. Soc. 1999, 121, 5099.

95. Williams, A. L.; Johnston, J. N.; J. Am. Chem. Soc. 2004, 126, 1612.

96. Sun, W.; Xia, C.-G.; Wang, H.-W.; Tetrahedron Lett. 2003, 44, 2409. 
97. Aggarwal, V. K.; Thompson, A.; Jones, R. V. H.; Standen, M. C. H.; J. Org Chem. 1996, 61, 8368.

98. Wright, D. L.; McMills, M. C.; Org. Lett. 1999, 1, 667.

99. Catino, A. J.; Nichols, J. M.; Forslund, R. E.; Doyle, M. P.; Org. Lett. 2005, 7, 2787; Doyle, M. P.; Hu, W.; Timmons, D. J.; Org. Lett. 2001, 3, 933.

100. Zhu, S.; Liao, Y.; Zhu, S.; Synlett 2005, 1429.

101. Aggarwal, V. K.; Alonso, E.; Ferrara, M.; Spey, S. E.; J. Org. Chem. 2002, 67, 2335.

102. Aggarwal, V. K.; Ferrara, M.; Org. Lett. 2000, 2, 4107.

103. Hori, R.; Aoyama, T.; Shioiri, T.; Tetrahedron Lett. 2000, 41, 9455.

104. Juhl, K.; Hazell, R. G.; Jorgensen, K. A.; J. Chem. Soc., Perkin Trans. 1 1999, 2293.

105. Vanderhoydonck, B.; Stevens, C. V.; Synthesis 2004, 722.

106. Arini, L. G.; Sinclair, A.; Szeto, P.; Stockman, R. A.; Tetrahedron Lett 2004, 45, 1589; Morton, D.; Pearson, D.; Field, R. A.; Stockman, R. A.; Org. Lett. 2004, 6, 2377.

107. Davis, F. A.; Deng, J.; Zhang, Y.; Haltiwanger, R. C.; Tetrahedron 2002, $58,7135$.

108. Kascheres, C. M.; J. Braz. Chem. Soc. 2003, 14, 945.

109. Pinho e Melo, T. M. V. D.; Lopes, C. S. J.; Rocha Gonsalves, A. M. d'A.; Beja, A. M.; Paixão, J. A.; Silva, M. R.; Veiga, L. A.; J. Org. Chem. 2002, 67, 66.

110. Palacios, F.; de Retana, A. M. O.; de Marigorta, E. M.; de los Santos, J. M.; Eur. J. Org. Chem. 2001, 2401.

111. Gilchrist, T. L.; Aldrichimica Acta 2001, 34, 51.

112. Barroso, M. T.; Kascheres, A.; J. Org. Chem. 1999, 64, 49.

113. Alves, M. J.; Fortes, G.; Guimarães, E.; Lemos, A.; Synlett 2003, 1403.
114. Alves, M. J.; Fortes, A. G.; Gonçalves, L. F.; Tetrahedron Lett. 2003, 44, 6277.

115. Davis, F. A.; Liang, C.-H.; Liu, H.; J. Org. Chem. 1997, 62, 3796.

116. Gilchrist, T. L.; Mendonça, R.; Arkivoc 2000, 1, 769.

117. Alves, M. J.; Fortes, A. G.; Lemos, A.; Martins, C.; Synthesis 2005, 555; Alves, M. J.; Fontes, A. G.; Costa, F. T.; Tetraedron 2006, 62, 3095.

118. Timén, Å. S.; Somfai, P.; J. Org. Chem 2003, 68, 9958.

119. Alves, M. J.; Durães, M. M.; Fortes, A. G.; Tetrahedron 2004, 60, 6541.

120. Pinho e Melo, T. M. V. D.; Cardoso, A. L.; Gomes, C. S. B.; Rocha Gonsalves, A. M. d'A.; Tetrahedron Lett. 2003, 44, 6313.

121. Voronkov, M. V.; Gontcharov, A. V.; Kanamarlapudi, R. C.; Richardson, P. F.; Wang, Z.-M.; Org. Process Res. Dev. 2005, 9, 221.

122. Kale, A. S.; Deshmukh, A. R. A. S.; Synlett 2005, 2370.

123. Ide, N. D.; Galonic, D. P.; van der Donk, W. A.; Gin, D. Y.; Synlett 2005, 2011.

124. Haga, T.; Ishikawa, T.; Tetrahedron 2005, 61, 2857.

125. Medjahed, W.; Zatla, A. T.; Mulengi, J. K.; Ahmed, F. Z. B.; Merzouk, H.; Tetrahedron Lett. 2004, 45, 1211.

126. Minakata, S.; Kano, D.; Oderaotoshi, Y.; Komatsu, M.; Angew. Chem., Int. Ed. 2004, 43, 79

127. Bräse, S.; Gil, C.; Knepper, K.; Zimmermann, V.; Angew. Chem., Int. Ed. 2005, 44, 5188.

128. Padwa, A.; Murphree, S. S.; Arkivoc 2006, 3, 6.

129. Watson, I. D. G.; Yu, L.; Yudin, A. K.; Acc. Chem. Res. 2006, 39, 194

130. Hirashita, T.; Toumatsu, S.; Imagawa, Y.; Araki, S.; Setsune, J.; Tetrahedron Lett. 2006, 47, 1613

131. Song, L.; Servajean, V.; Thierry, J.; Tetrahedron 2006, 62, 3509. 